\title{
Consequências da Vasectomia: experiência de homens que se submeteram à cirurgia em Campinas (São Paulo), Brasil
}

\author{
Consequences of Vasectomy: experience of men who \\ underwent the surgery in Campinas (São Paulo), Brazil
}

\author{
Nádia Maria Marchi \\ Enfermeira. Doutora em Saúde Pública. Pesquisadora do Ambula- \\ tório de Reprodução Humana, Departamento de Tocoginecologia, \\ da Faculdade de Ciências Médicas da UNICAMP. \\ Endereço: Rua Vital Brasil, 200, Cidade Universitária, CEP 13083- \\ 888, Campinas, SP, Brasil. \\ E-mail: nmarchi®uol.com.br
}

\section{Augusta Thereza de Alvarenga}

Socióloga. Doutora em Saúde Pública. Professora Doutora da Faculdade de Saúde Pública da USP.

Endereço: Av Dr Arnaldo 715, Cerqueira Cesar, CEP 01246-904, São Paulo, SP, Brasil.

E-mail: atalळusp.br

\section{Maria José Duarte Osis}

Socióloga. Doutora em Saúde Pública. Pesquisadora junto ao Departamento de Pesquisas Sociais do Centro de Pesquisas em Saúde Reprodutiva de Campinas (Cemicamp). Professora colaboradora voluntária do Departamento de Tocoginecologia da FCM/UNICAMP.

Endereço: Rua Vital Brasil, 200, Cidade Universitária, CEP 13083888, Campinas, SP, Brasil.

E-mail: mjosisळcemicamp.org.br

\section{Helena Maria de Aguiar Godoy}

Médica. Coordenadora do Ambulatório de Planejamento Familiar da Prefeitura Municipal de Campinas.

Endereço: Av. Dr. Campos Sales, 737, 7 andar, Centro, CEP 130ı08ı, Campinas, SP, Brasil.

E-mail: helenamagodoyळgmail.com

\section{Maria Cecília Borges Guimarães}

Assistente Social do Ambulatório de Planejamento Familiar da Prefeitura Municipal de Campinas.

Endereço: Av. Dr. Campos Sales, 737, 7 andar, Centro, CEP 1301008I, Campinas, SP, Brasil.

E-mail: ceciliaguimaraes2010œhotmail.com

\section{Luis Bahamondes}

Médico. Professor Titular de Ginecologia do Departamento de Tocoginecologia, Faculdade de Ciências Médicas da Universidade Estadual de Campinas - UNICAMP

Endereço: Rua Vital Brasil, 200, Cidade Universitária, CEP 13083888, Campinas, SP, Brasil.

E-mail: bahamondळcaism.unicamp.br

\section{Resumo}

Objetivo: Descrever a experiência de homens vasectomizados há pelo menos um ano em serviços públicos de saúde de Campinas, Estado de São Paulo. Procedimentos metodológicos: estudo descritivo com um componente qualitativo e outro quantitativo. Para a etapa qualitativa, realizaram-se 10 entrevistas semiestruturadas com homens selecionados de acordo com critérios propositais de escolaridade e número de filhos. Em seguida, foi aplicado um formulário estruturado a 202 homens, sorteados a partir da lista completa daqueles que haviam sido vasectomizados entre 1998 e 2004. Realizou-se análise temática do conteúdo das entrevistas semiestruturadas. Os dados quantitativos foram digitados e foi realizada análise descritiva. Resultados: Observou-se que 97\% dos homens estavam satisfeitos por terem feito a cirurgia e poucos referiram efeitos indesejados. Entre os poucos homens insatisfeitos, apenas um havia feito a reversão da cirurgia porque vivia com uma nova companheira e queria ter filhos; entre os demais a insatisfação devia-se à dor provocada pelo procedimento cirúrgico. A maioria dos entrevistados atribuiu à vasectomia mudanças para melhor sobre sua saúde, corpo, relacionamento em geral com a família e com a esposa, na vida sexual e na situação econômica. Prevaleceu a ideia de que a vasectomia só trouxera benefícios. A possibilidade de arrependimento foi mencionada pelos entrevistados como algo que não aconteceria com eles. Conclusão: Os resultados deste estudo permitiram verificar que os homens que optam pela vasectomia tendem a ver o método como fator de mudanças positivas, principalmente sobre a vida sexual e o relacionamento com a companheira e a família em geral.

Palavras-chave: Saúde pública; Saúde coletiva; Saúde sexual e reprodutiva; Vasectomia. 


\section{Abstract}

Objective: To describe the experience of men who had a vasectomy at least one year before at public healthcare services at Campinas, State of São Paulo. Methodological procedures: descriptive study with a qualitative and a quantitative component. In the qualitative stage, 10 semi-structured interviews were performed with men selected according to purposeful criteria of level of schooling and number of children. Then, a structured form was provided for 202 men, drawn from the complete list of those who had had a vasectomy between 1998 and 2004. A thematic analysis of the content of the semi-structured interviews was carried out. The quantitative data were keyboarded and a descriptive analysis was conducted. Results: It was observed that $97 \%$ of the men were satisfied because they had undergone the surgery and only a few of them mentioned undesired effects. Among the few dissatisfied men, only one had had vasectomy reversal because he lived with a new partner and wanted to have children; among the others, dissatisfaction was due to the pain caused by the surgical procedure. The majority of the interviewees attributed to vasectomy changes for the best in their health, body, general relationship with their families and wives, in their sexual life and economic situation. The idea that prevailed was that vasectomy had brought only benefits. The possibility of regret was mentioned by the interviewees as something that would not happen to them. Conclusion: The results of this study allowed to verify that men who decide to have a vasectomy tend to see the method as a factor of positive changes, mainly in the sexual life and in the relationship with the partner and family in general.

Keywords: Public Health; Sexual and Reproductive Health; Vasectomy.

\section{Introdução}

A vasectomia, um dos poucos métodos contraceptivos de uso masculino, embora seja bastante utilizada em países desenvolvidos, como Austrália, Canadá, Holanda e Estados Unidos, apresenta baixa prevalência de uso na maioria dos países em desenvolvimento, incluindo os da América Latina (Potts e col., 1999; Pile e Barone, 2009). No Brasil, sua prevalência, apesar de ter aumentado nos últimos anos, é ainda baixa e pouco se sabe sobre como os homens que se submetem à cirurgia vivenciam a sua nova condição de esterilizados.

No Brasil, em 1986, o,8\% das mulheres unidas referiram que seus companheiros estavam vasectomizados (Arruda e col., 1987); essa proporção foi de 2,6\% em 1996 (BEMFAM e Macro Internacional, 1997) e chegou a 5,1\% em 2006 (Brasil, 2008). Apesar da baixa prevalência nacional, há diferenças regionais e indícios de que se encontra em expansão (Marchi e col., 2010). Na Região Sudeste, a mais desenvolvida do país, a prevalência é de $8,3 \%$ em comparação com o,8\% na Região Norte (Brasil, 2008).

Campinas, no Estado de São Paulo, é sede de uma das maiores regiões metropolitanas do Brasil e, desde os anos 1980, apresenta prevalência de vasectomia bem acima da nacional, em torno de 10\% (Duarte e col., 2003; Carvalho e col., 2007). Estudo em que se avaliaram as características dos homens vasectomizados em Campinas, entre 1998 e 2004, apontou que havia acesso da população de baixa renda à vasectomia na rede pública de saúde do município, porém com grande tempo de espera entre a solicitação e a realização da cirurgia (Marchi e col., 2010).

Existe uma lacuna de conhecimento em relação à esterilização cirúrgica masculina no Brasil no que se refere às possíveis consequências da opção por esse método na vida dos homens que se submetem à cirurgia. Isso, provavelmente, seja resultado de sua baixa prevalência e popularidade em nosso meio até recentemente, quando a situação parece estar se modificando. Os estudos já realizados tendem a abordar o processo de decisão pela vasectomia e a expectativa dos homens com relação ao que ocorrerá no futuro (Marchi, 2003). Identificaram-se apenas outros dois estudos em que se abordou a experiência 
de homens vasectomizados, ambos realizados em São Paulo. Manhoso e Hoga (2005) apontaram, em estudo qualitativo, que os homens relataram vários receios em relação à vasectomia, principalmente quanto à sua desvalorização como homens. Porém, todos se disseram satisfeitos por terem feito a vasectomia e mencionaram vários aspectos positivos, como a melhora no relacionamento sexual com as parceiras, especialmente pela superação do medo de uma gravidez indesejada, assim como o afastamento das preocupações e atribulações com o uso anterior de métodos anticoncepcionais. Nenhum dos participantes referiu medo de arrepender-se. Também em São Paulo, estudo prospectivo de Bertero e colaboradores (2005) acompanhou 65 homens que fizeram a vasectomia em hospital universitário e realizou avaliações antes da cirurgia e 90 dias depois, concluindo que a vasectomia produziu um efeito positivo na função sexual dos homens, especialmente sobre o desejo e a satisfação.

Neste artigo apresentam-se os resultados de um estudo com homens vasectomizados há pelo menos um ano em serviços públicos de saúde de Campinas, em que se investigou a sua experiência com a vasectomia.

\section{Sujeitos e Métodos}

Foi realizado um estudo misto, com abordagem quantitativa e qualitativa. Para a primeira, desenvolveu-se um estudo descritivo, de corte transversal, em que se selecionou uma amostra dentre os 2.399 homens que haviam sido vasectomizados e que passaram pelo processo de obtenção da vasectomia no Ambulatório de Planejamento Familiar da Prefeitura Municipal de Campinas (APF) entre 1998 e 2004. 0 tamanho da amostra foi calculado em 267 homens com base no trabalho de Rodrigues e colaboradores (2003), considerando-se uma proporção estimada de 50\% de homens que referiam sentir-se melhor no casamento após a vasectomia, e uma diferença absoluta desejada entre as proporções amostral e populacional de sete pontos percentuais e $\alpha$ de $5 \%$. 0 tamanho efetivo da amostra foi de 202 homens, implicando perda de precisão de aproximadamente um ponto percentual, ou seja, a diferença absoluta entre as proporções amostral e populacional passou a sete pontos percentuais. A coleta dos dados ocorreu ao longo do ano de 2005.
Os homens sorteados foram entrevistados por pessoas treinadas, que aplicaram formulário estruturado e pré-testado. O formulário utilizado constava de três seções, uma das quais abordava a experiência dos homens com a condição de vasectomizados. Os formulários preenchidos foram conferidos e digitados duas vezes, por pessoas distintas, através do módulo data entry do programa computacional SPSS, para constituição do banco de dados. Para a análise dos dados foram preparadas tabelas com a distribuição de frequências das principais variáveis.

Para a abordagem qualitativa, a partir da listagem dos homens vasectomizados no APF-PMC, acima referida, foi tomada uma amostra intencional de 12 homens, contatados via telefone ou correio e convidados a participar de uma entrevista semiestruturada. A seleção foi feita levando-se em conta idade, escolaridade e número de filhos dos homens, variáveis que têm mostrado relação com a opção pela vasectomia (Berquó e Cavenaghi, 2003). Estabeleceram-se quatro grupos, conforme a combinação dessas variáveis:

Grupo 1: Escolaridade fundamental, até 29 anos de idade, até dois filhos vivos;

Grupo 2: Escolaridade média/superior, até 29 anos de idade, até dois filhos vivos;

Grupo 3: Escolaridade fundamental, 30 anos ou mais de idade, três ou mais filhos;

Grupo 4: Escolaridade média/superior, 30 anos ou mais de idade, três ou mais filhos.

A combinação de idade, escolaridade e número de filhos nos Grupos 1 e 3 visou a representar qualitativamente os homens menos propensos à opção pela vasectomia, em vista de sua escolaridade, enquanto os Grupos 2 e 4 representaram qualitativamente homens mais propensos a optar pela esterilização cirúrgica. Dentro de cada grupo de escolaridade buscou-se também representar a variedade quanto à idade e o número de filhos. Dois dos homens inicialmente identificados na listagem do APF para participar da fase qualitativa não foram localizados, de maneira que foram entrevistados 10 homens. À medida que as entrevistas foram sendo feitas, observou-se se havia saturação das informações quanto à percepção de consequências da vasectomia na vida dos entrevistados, de modo que não foi 
necessário entrevistar mais homens do que os que foram identificados inicialmente. As entrevistas foram realizadas pela pesquisadora principal (NM), gravadas e transcritas integralmente. Posteriormente, os textos foram inseridos no programa The Ethnograph (Seidel, 1998), para facilitar a análise temática de seu conteúdo. A análise temática foi realizada com base nas orientações de Minayo (1998), buscando desvelar as unidades de significado ou temas identificados nas falas dos homens, bem como detectar os valores de referência e os modelos de comportamento revelados no discurso dos sujeitos. A partir da identificação desses temas foram estabelecidas categorias gerais e específicas, conforme sua frequência de aparição, relacionadas à percepção dos homens quanto às consequências da vasectomia em algumas áreas de sua vida. Neste artigo são apresentados os resultados da análise das seguintes categorias:

- Aspectos positivos e negativos: consequências da vasectomia na vida dos homens, segundo sua própria percepção;

- Arrependimento: ocorrência de arrependimento pós-vasectomia e opinião dos homens sobre essa possibilidade.

Foi obtida a devida autorização do(a) responsável pelo APF-PMC para a revisão dos prontuários dos homens submetidos à vasectomia, bem como para convidá-los a participar voluntariamente do estudo. Os homens sorteados foram contatados para participar da pesquisa voluntariamente, de acordo com as normas brasileiras para pesquisas envolvendo seres humanos (Conselho Nacional de Saúde, 1996). O protocolo foi aprovado pelo Comitê de Ética em Pesquisa da Faculdade de Saúde Pública da Universidade de São Paulo, em agosto de 2003 (Protocolo 994).

\section{Resultados}

A maioria dos homens que participaram da abordagem quantitativa do estudo tinha entre 30 e 39 anos de idade $(78,1 \%)$ no momento da cirurgia; $62,2 \%$ haviam cursado até a $8^{a}$ série do Ensino Fundamental; 57,3\% declararam outra cor da pele, que não branca, e 64,2\% disseram ser da religião católica; $61,7 \%$ tinham renda per capita familiar de até R\$30o,oo. Cerca da metade (52,7\%) dos homens vasectomizados tinha no máximo dois filhos. A maioria (67\%) tinha filhos de ambos os sexos quando fez a vasectomia, e mais de 3/4 deles referiram que tiveram todos os filhos com a companheira atual (78,1\%). Por ocasião da entrevista, quase a totalidade $(95,5 \%)$ dos homens estudados conviviam com a mesma companheira da época da cirurgia (dados não apresentados em tabelas).

A grande maioria dos homens entrevistados disse estar satisfeita ou muito satisfeita com a vasectomia (97\%), e as razões expostas para isso com maior frequência foram já ter o número ideal de filhos/não quererem ter mais filhos e considerarem que o método não falha/dá segurança. Quase $4 / 5$ dos entrevistados disseram que a vasectomia trouxe benefícios à sua vida. Apenas seis homens (3,0\%) referiram estar insatisfeitos ou pouco satisfeitos por terem se submetido à vasectomia. Três desses homens disseram que a cirurgia foi mal feita e eles tinham muita dor; um referiu que precisou refazer a cirurgia; outro se referiu a ter demora para atingir o orgasmo. Houve um homem que disse ter se divorciado e casado novamente, razão pela qual voltou a querer ter filhos (Tabela 1).

Pouco mais da metade dos entrevistados atribuiu à vasectomia mudanças para melhor sobre sua saúde, corpo, relacionamento em geral com a família e situação econômica. Quase 2/3 referiram-se a esse tipo de mudanças na vida sexual e no relacionamento em geral com a esposa (Tabela 2). Quando se analisou a relação entre ter referido essas mudanças para melhor e viver ou não atualmente com a mesma companheira da época da cirurgia, não se observaram diferenças significativas (Tabela 3). Ao avaliar a relação entre as mudanças percebidas pelos homens em algumas áreas de sua vida e o tempo decorrido desde a cirurgia, observou-se que as mudanças para melhor, em geral, não variaram significativamente. As mudanças na saúde, no corpo, no relacionamento em geral com a família e a situação econômica mantiveram-se em torno da metade dos homens. Entretanto, a referência de mudanças para melhor na vida sexual e no relacionamento com a companheira decresceram levemente no decorrer do tempo, mas sem diferença significativa e mantendo-se na faixa de $60-65 \%$ (Tabela 4 ). 
Tabela I - Número e proporção (\%) de homens vasectomizados segundo a satisfação com a vasectomia e razões. Campinas, SP

\begin{tabular}{|c|c|c|}
\hline Satisfação & $n^{\circ}$ & $\%$ \\
\hline Satisfeitos ou muito satisfeitos & 196 & 97,0 \\
\hline Insatisfeitos ou pouco satisfeitos & 6 & 3,0 \\
\hline \multicolumn{3}{|l|}{ Razões para estarem satisfeitos/muito satisfeitos\# } \\
\hline Têm o número ideal de filhos/não querem ter mais filhos & 116 & 59,2 \\
\hline Não falha/dá segurança & 59 & 30,1 \\
\hline Não precisa lembrar-se de usar/colocar & 50 & 25,5 \\
\hline Ficaram mais soltos/mais livres para ter relação sexual & 46 & 23,5 \\
\hline A companheira não precisa mais usar métodos que Ihe faziam mal & 44 & 22,4 \\
\hline A companheira está satisfeita & 37 & 18,9 \\
\hline Não faz mal à saúde & 30 & 15,3 \\
\hline Outro & 11 & 5,6 \\
\hline Não teve problemas/deu tudo certo & 9 & 4,6 \\
\hline \multicolumn{3}{|l|}{ A vasectomia trouxe/tem trazido* } \\
\hline Benefícios & 160 & 79,6 \\
\hline Prejuízos & 3 & 1,5 \\
\hline Nem uma coisa nem outra & 36 & 17,9 \\
\hline Não sabiam avaliar & 2 & 1,0 \\
\hline Total de homens & 202 & \\
\hline \multicolumn{3}{|l|}{ Razões para estar pouco satisfeito/insatisfeito } \\
\hline Cirurgia malfeita/muita dor & 3 & 50 \\
\hline Demora para atingir o orgasmo & 1 & 17 \\
\hline Arrependeu-se porque se casou outra vez & 1 & 17 \\
\hline A primeira cirurgia não deu certo, precisou fazer de novo & 1 & 17 \\
\hline Total de homens & 6 & \\
\hline
\end{tabular}

\# Cada entrevistado podia dar mais de uma resposta.

* Faltou informação de um homem.

Tabela 2 - Número e proporção (\%) de homens vasectomizados segundo mudanças atibuidas à vasectomia. Campinas, SP

\begin{tabular}{lcccc} 
& \multicolumn{2}{c}{ Para melhor } & \multicolumn{2}{c}{ Para pior } \\
Mudanças & $n^{\circ}$ & $\%$ & $n^{\circ}$ & $\%$ \\
Na saúde & 106 & 52,2 & - & - \\
No corpo & 103 & 50,7 & - & - \\
Na vida sexual & 137 & 67,5 & 4 & 2,0 \\
No relacionamento em geral com a esposa/ companheira & 133 & 65,5 & 2 & 1,0 \\
No relacionamento em geral com a família & 108 & 53,2 & - & - \\
Na situação econômica & 119 & 58,6 & 2 & 1,0 \\
\hline
\end{tabular}


Tabela 3 - Número e proporção (\%) de homens vasectomizados segundo mudanças percebidas por eles em algumas áreas de sua vida e convivência atual com a mesma companheira da época da cirurgia

\begin{tabular}{|c|c|c|c|c|}
\hline \multirow[b]{3}{*}{ Mudanças } & \multicolumn{4}{|c|}{ Convivência atual com a mesma companheira } \\
\hline & \multicolumn{2}{|c|}{ Sim } & \multicolumn{2}{|c|}{ Não } \\
\hline & $n^{0}$ & $\%$ & $n^{\circ}$ & $\%$ \\
\hline Saúde melhor & 104 & 53,9 & 2 & 22,2 \\
\hline Corpo melhor & 101 & 52,3 & 2 & 22,2 \\
\hline Vida sexual & 132 & 68,4 & 5 & 55,6 \\
\hline Relacionamento em geral com a esposa/companheira & 126 & 65,3 & 7 & 77,8 \\
\hline
\end{tabular}

Tabela 4 - Número e proporção (\%) de homens vasectomizados segundo mudanças para melhor percebidas por eles em algumas áreas de sua vida e tempo decorrido desde a cirurgia

\begin{tabular}{|c|c|c|c|c|c|c|}
\hline \multirow{3}{*}{ Mudanças } & \multicolumn{6}{|c|}{ Tempo decorrido desde a cirurgia (anos) } \\
\hline & \multicolumn{2}{|c|}{$1-2$} & \multicolumn{2}{|c|}{$3-4$} & \multicolumn{2}{|c|}{$\geq 5$} \\
\hline & $n^{0}$ & $\%$ & $n^{0}$ & $\%$ & $n^{0}$ & $\%$ \\
\hline Saúde & 31 & 50,0 & 40 & 54,1 & 34 & 52,3 \\
\hline Corpo & 30 & 48,4 & 39 & 52,7 & 33 & 50,8 \\
\hline Vida sexual & 44 & 71,0 & 50 & 67,6 & 42 & 64,6 \\
\hline Relacionamento em geral com a esposa/ompanheira & 42 & 67,7 & 46 & 62,2 & 44 & 67,7 \\
\hline Relacionamento em geral com a família & 32 & 51,6 & 43 & 58,1 & 32 & 49,2 \\
\hline Situação econômica & 35 & 56,5 & 47 & 63,5 & 36 & 55,4 \\
\hline
\end{tabular}

Em relação ao arrependimento e solicitação de reversão, oito homens disseram que chegaram a se arrepender, seis deles pensaram em desfazer a vasectomia, dentre os quais apenas um chegou a solicitar e obteve reversão. Este foi o único entrevistado que apresentou como motivo de insatisfação uma condição relativa ao efeito contraceptivo da vasectomia, pois se casara novamente e desejava ter filhos com a nova companheira, embora já tivesse dois filhos com a pessoa com quem convivia na época da cirurgia. Os demais insatisfeitos mencionaram razões relativas a sequelas do procedimento cirúrgico (dados não apresentados em tabelas).

Nas entrevistas semidirigidas foi possível observar que os homens percebiam os benefícios da vasectomia em relação à maior tranquilidade nas relações sexuais, uma vez afastado o medo de gravidez, o que repercutia em todo o relacionamento conjugal e também familiar:
- Como tem sido a sua experiência de ter feito a cirurgia, como o senhor se sente?

- Ah, muito bem, muito aliviado, é... você não tem mais aquela preocupação, por que filhos hoje é um problema sério, são bênçãos na nossas vidas, mas são problemas assim se for mal, mal programado, é um problema sério, né, então tem sido uma, tem sido muito bom, não ter mais a preocupação de evitar filho né, como se diz.

- Quais as mudanças positivas que a cirurgia trouxe na, para sua vida?

- Bom, não sei se eu vou saber colocar, mais... bom uma coisa, que nem eu acabei de falar aqui, você tem a tranquilidade, não tem mais preocupação, é... o relacionamento entre eu e minha esposa... ficou melhor, vamos dizer assim, por que acho que tudo que você, quando o casaléresponsável, tudo que se vai fazer com relação a... entre uma 
relação sexual é... é preocupante, é... inspira preocupação, então eu acho que isso amenizou tudo isso aí, é... ficou mais, é... como é que se diz, ficou melhor, ficou mais... não sei colocar as palavras certa, mas foi muito bom, melhorou...

- E além da parte sexual? O que o senhor acha que trouxe de positivo? Como que tem sido essa experiência, além da parte sexual?

- Bom, é... eu vou achar as palavras aqui, ah... eu.... então, é... eu acho que... desde o momento que você tem a tranquilidade na sua relação isso gera uma harmonia assim... no relacionamento, que nem vocêfalou sem ser na parte sexual entre minha esposa né, a nossa... a nossa relação no dia a dia, a nossa comunicação, enfim ficou... melhorou muito, é... não existe mais aquele, aquela preocupação pós relação sexual, vamos dizer assim, do que vai ser o que não vai ser, será que evitou ou não, mas é... ficou a nossa, a nossa relação assim, a nossa união, eu acho que ela tem se constituído cada vez mais né, entre eu e ela por que eu queria e ela queria também então eu acho que, acho não, tenho certeza que foi $100 \%$, foi bom. (Entrevistado $\mathrm{n}^{\circ} \mathrm{1}$ )

Os homens pouco falaram sobre aspectos negativos da vasectomia, refletindo o que se verificou também na etapa quantitativa. Ao abordar o que poderia ser negativo na experiência de ter feito vasectomia, as falas dos entrevistados mencionaram o medo de a vasectomia falhar e a companheira voltar a engravidar, e a possibilidade de arrependimento, caso o homem deseje ter mais filhos com uma nova companheira, ou ocorra morte dos filhos, ou a mulher insista muito em ter outro filho. Porém, os entrevistados disseram que na sua experiência, até aquele momento, isso não acontecia.

- O negativo é se você se arrepender, eu acho que o negativo ele só existe se você se arrepender, no caso de você falar assim, não, não era isso que eu queria... os pontos negativoéesse, eu acho assim, se você se arrepender, se você se arrepender é negativo por que aí não tem retorno ... poderia sanar isso se tivesse congelado esperma, eu não fiz isso, hoje se eu tivesse que fazer vasectomia hoje eu faria isso, eu congelaria esperma no caso de um arrependimento, ou um problema futuro na família, em desastre, qualquer coisa assim, aí tudo bem, ou um novo relacionamento, a pessoa não ter filho e queria ter esse filho de todo jeito, eu poderia dizer, oh, eu não tenho no meu corpo prá te dar, mas eu tenho no banco de esperma prá poder fazer isso, seria esse o arrependimento, mas hoje eu não tenho arrependimento nenhum, hoje o ponto negativo prá mim da vasectomia não existe prá mim, hoje no momento. (Entrevistado $\mathrm{n}^{\circ}$ 6)

- Cem por cento não. Cem por cento não, não confio, eu tenho muito medo de engravidar, não quero mais ter filhos, né, não quero, me arrependo, assim ... logicamente, eu amo meus filhos, né, hoje é o que eu tenho mais de precioso na minha vida são eles, mas, eles estão aí não é por acaso, mas assim, se eu, assim, uma coisa assim, que nunca foi uma coisa forte em mim équerer ser pai, nunca foi uma coisa forte em mim, foi uma coisa assim quase que nula. (Entrevistado $\mathrm{n}^{\circ} 8$ )

\section{Discussão}

Os resultados deste estudo permitiram verificar que os homens que optam pela vasectomia tendem a ver o método como fator de mudanças positivas, principalmente sobre a vida sexual e o relacionamento com a companheira e a família em geral. Foi comum a referência a terem "ficado mais soltos" para as relações sexuais, o que evidencia a permanência de sua virilidade, requisito imprescindível à masculinidade hegemônica. Por outro lado, os homens enfatizaram a melhora nas relações familiares como consequência da tranquilidade de poder ter relações sexuais sem medo de uma gravidez indesejada que comprometeria sua capacidade como provedor da família. Quando se comparam esses resultados com aqueles verificados em estudos com mulheres laqueadas (Minella, 1998; Osis e col., 1999), observa-se que a percepção de mudanças positivas nessas áreas é bem mais intensa do que a que também ocorre entre as mulheres. Os homens que se submetem à vasectomia percebem sua nova condição como sendo de lucro no que diz respeito à sua identidade de gênero. Para as mulheres, os primeiros momentos pós-laqueadura são vistos como conquista, como liberdade da batalha diária da contracepção. Porém, 
na sequência de sua trajetória de vida, a condição de laqueada pode representar perdas em sua identidade de gênero (Serruya, 1996; Minella, 1998; Osis e col., 1999; Osis, 2001).

Em São Paulo, Manhoso e Hoga (2005) apontaram que homens vasectomizados estavam satisfeitos por terem feito a vasectomia e mencionaram vários aspectos positivos, como a melhora no relacionamento sexual com as parceiras, especialmente pela superação do medo de uma gravidez indesejada, assim como o afastamento das preocupações e atribulações com o uso anterior de métodos anticoncepcionais. Nenhum dos participantes referiu medo de arrepender-se.

Em outros países identificam-se vários estudos que abordam a experiência de homens vasectomizados. Philliber e Philliber (1985) revisaram a literatura publicada entre 1972 e 1984, referente às pesquisas sociais acerca dos antecedentes e das consequências da esterilização cirúrgica masculina. De modo geral, esses autores concluíram que existia uma tendência a melhorar as relações maritais após a cirurgia e que a maioria dos homens não relatava mudanças em sua atividade sexual. Estudo prospectivo realizado na África do Sul por Hofmeyr e Greeff (2002) não observou diferenças significativas quanto à satisfação sexual, satisfação com o relacionamento marital, comunicação e frequência das relações sexuais, avaliadas antes da vasectomia e cerca de cinco meses depois. No mesmo sentido, Smith e colaboradores (2009) não encontraram diferenças entre homens australianos vasectomizados e não vasectomizados com respeito à prevalência de problemas sexuais. Melville e Bigrigg (2008), ao revisar estudos sobre esse tema, apontaram que cerca de $1 \%$ dos homens pode apresentar problemas psicossexuais após a vasectomia.

Thonneau e D’Isle (1990) fizeram uma revisão de trabalhos publicados acerca dos possíveis efeitos da vasectomia e apontaram que os estudos em questão não indicavam alterações significativas quanto ao número de relações sexuais nem quanto ao desejo sexual dos homens. Por outro lado, apontaram evidências de um grande leque de sintomas com repercussões psicossociais surgidos após a vasectomia, como dor de cabeça, desordens de ejaculação, alcoolismo, sentimento de inferioridade, estados psicóticos, hipocondria, fantasias de castração nas parceiras dos homens vasectomizados. Porém, os autores chamam a atenção para o fato de que esses sintomas foram identificados com maior frequência nos estudos mais antigos (1965-1979), o que poderia ser atribuído a um menor conhecimento sobre a vasectomia e maior preocupação quanto às suas consequências. Ao mesmo tempo, observou-se que nos trabalhos revisados havia pouca referência a mudanças positivas atribuídas à vasectomia, o que, na interpretação dos autores, poderia estar relacionado à forma como o tema era abordado, razão pela qual consideram importante a realização de estudos enfocando a experiência da vida real dos homens submetidos à esterilização cirúrgica, o que foi feito em nosso estudo.

Ao lado dessa perspectiva de benefícios da vasectomia no que se refere à maior liberdade para a vida sexual, os homens que participaram desta pesquisa evidenciaram também a ideia de que a vasectomia tinha sido uma boa opção porque lhes permitia exercer o papel de provedor da família dentro de suas possibilidades reais, evitando novas gravidezes indesejadas. Vale lembrar que dentro da perspectiva tradicional das relações de gênero em nossa sociedade, os homens tenderiam a considerar que as mulheres é que coordenam o processo reprodutivo, porque ocorre no corpo delas. Por vezes, os homens podem, inclusive, expressar ressentimento a esse respeito, por sentirem-se 'obrigados' pelas mulheres a mudar o rumo de suas vidas e tornarem-se pais quando não queriam. Porém, o tornar-se pai é, ao mesmo tempo, sinônimo de assumir responsabilidade social, de ser visto socialmente como um homem maduro, sério, qualquer que seja a concepção de masculinidade em que se esteja pensando (Arilha, 1999). Nesse contexto, a identidade masculina se firma na esfera pública, legitimando o papel do homem como provedor e protetor da família (Bandeira, 1999). Mais ainda, historicamente na cultura ocidental vem predominando o ser "bom provedor" como elemento distintivo da masculinidade (Engle e Leonard, 1998).

Embora não tenha sido relevante neste estudo, é preciso pensar que existe a possibilidade de arrependimento pós-esterilização masculina. Neste estudo apenas um homem manifestou-se arrependido, e 
suas características levam a refletir sobre quais circunstâncias seriam mais propícias a esse evento: ele fez a vasectomia com 28 anos e dois filhos, atendendo plenamente às normas legais. Entretanto, casou-se novamente e, com isso, desejou filhos com a nova parceira, o que o levou a pedir e fazer a reversão. Os estudos internacionais sobre arrependimento pós-vasectomia enfatizam o fator idade como sendo um dos mais relevantes no fenômeno do arrependimento, ao lado da qualidade do relacionamento conjugal dos candidatos à vasectomia (Howard, 1982; Potts e col., 1999; Miller e col., 1991; Rungby e col., 1994; Jamieson e col., 2002; Melville e Bigrigg, 2008). Em vista disso, a qualidade da informação dada aos homens antes da vasectomia é considerada fundamental para evitar o arrependimento (Rungby e col., 1994; Melville e Briggig, 2008; Glasier, 2010; Labrecque e col., 2010). Especialmente, salienta-se que essa informação deve abordar as alternativas contraceptivas e possíveis problemas no relacionamento sexual.

A Lei 9.263, de 12 de Janeiro de 1996, artigo $1^{\circ}$, parágrafo 1: exige que os serviços que realizam a esterilização cirúrgica disponham de todos os métodos anticoncepcionais e realizem ações educativas com os candidatos à esterilização cirúrgica, "incluindo aconselhamento por equipe multidisciplinar, visando desencorajar a esterilização precoce" (Brasil, 1996). Na amostra estudada, todos os homens haviam passado por um processo de múltiplas etapas até serem vasectomizados, incluindo a participação em palestras e atividades educativas no APF (Marchi e col., 2010). Porém, sabe-se que essa não é a situação mais frequente no país e nem mesmo na Região Metropolitana de Campinas (RMC). Estudo recente em quatro capitais brasileiras (Osis e col., 2006) apontou que a disponibilidade e variedade de métodos anticoncepcionais continuam a ser problemas para o acesso efetivo da população ao planejamento familiar, que as ações educativas nessa área não buscam ativamente a participação dos homens, e que a presença deles nas unidades básicas de saúde costuma restringir-se à condição de acompanhantes das mulheres ou para retirar preservativos visando à prevenção de doenças transmitidas sexualmente. Pesquisa realizada nos 19 municípios da RMC também apontou que os homens vasectomizados a partir de 1998, já na vigência da Lei de Planejamento Familiar (Lei n. 9.263), ainda assim, em sua grande maioria, não haviam recebido informações sobre a vasectomia durante o processo de obtenção da cirurgia (Carvalho e col., 2007). Entretanto, a preocupação com a possibilidade de arrependimento não deve criar obstáculos para que as pessoas tenham acesso à esterilização cirúrgica. Ao contrário, deve impulsionar a oferta de atenção de boa qualidade ao planejamento familiar como um dos componentes da saúde e dos direitos sexuais e reprodutivos.

Não se pode ignorar que há pessoas que desejam adiar ou espaçar gravidezes, assim como aquelas que desejam encerrar sua trajetória reprodutiva. Ambas precisam dispor de alternativas adequadas ao seu desejo e às suas condições de vida. Nesse sentido, a atenção em planejamento familiar de boa qualidade é essencial para que se respeitem os direitos dessas pessoas, bem como é parte das ações preventivas em saúde pública. As ações em planejamento familiar são essenciais para evitar gravidezes indesejadas e, consequentemente, abortos, que, por serem ilegais, na maioria das vezes são inseguros e podem trazer graves prejuízos às mulheres, suas famílias e, em última instância, à sociedade em geral. Ao mesmo tempo, a disponibilidade e o acesso aos métodos anticoncepcionais são imprescindíveis para evitar gravidezes de alto risco que podem resultar em morbimortalidade materna grave (Sonfield, 2010). É preciso lembrar que, no marco dos direitos sexuais e reprodutivos, no que se refere à anticoncepção, a meta deve ser sempre a de avançar no sentido de prover às pessoas informação e acesso ao mais amplo leque de métodos contraceptivos, o que inclui a esterilização cirúrgica masculina.

\section{Referências}

ARILHA, M. Homens, saúde reprodutiva e gênero: o desafio da inclusão. In: GIFFIN, K.; COSTA, S. H.(orgs.). Questões de saúde reprodutiva. Rio de Janeiro: Fiocruz, 1999. p. 455-67.

ARRUDA, J. M. Pesquisa nacional sobre saúde materno-infantil e planejamento familiar PNSMIPF - Brasil 1986. Rio de Janeiro: BEMFAM, 1987. 
BANDEIRA, L. Relações de gênero, corpo e sexualidade. In: GALVÃO, L.; DÍAZ, J. (orgs.). Saúde sexual e reprodutiva no Brasil. São Paulo: HUCITEC/Population Council, 1999. p.18o-97.

BEMFAM - Sociedade Civil Bem Estar Familiar no Brasil; MACRO Internacional. Programa de Pesquisas de Demografia e Saúde. Brasil: pesquisa nacional sobre demografia e Saúde 1996. Rio de Janeiro: BEMFAM; 1997.

BERQUÓ, E.; CAVENAGHI, S. Direitos reprodutivos de mulheres e homens face à nova legislação sobre esterilização voluntária. Cadernos de Saúde Pública, Rio de Janeiro, v. 19, Sup. 2, p. S441-453, 2003.

BERTERO, E. et al. Assessment of sexual function in patients undergoing vasectomy using the international index of erectile function. International Brazilian Journal of Urology, Rio de Janeiro, v. 31, n. 5, p. 452-458, 2005.

BRASIL. Lei ordinária ${ }^{0}$ 9263, de 12 de janeiro de 1996. Regula o parágrafo 7 do artigo 226 da Constituição Federal, que trata do planejamento familiar, estabelece penalidades e dá outras providências; partes vetadas correspondentes aos artigos 10, 11, 14 e 15. Diário Oficial da União. 20 ago. 1997; Seção 1, p. 17989.

BRASIL. Ministério da Saúde. Pesquisa Nacional de Demografia e Saúde da Criança e da Mulher, 20o6. Brasília: Ministério da Saúde, 2008.

CARVALHO, L. E. C. et al. Esterilização cirúrgica voluntária na Região Metropolitana de Campinas, São Paulo, Brasil, antes e após sua regulamentação. Cadernos de Saúde Pública, Rio de Janeiro, v. 23, n. 12, p. 2906-2916, 2007.

CONSELHO Nacional de Saúde. Resolução ${ }^{\circ}$ 196/96. Dispõe sobre pesquisas envolvendo seres humanos. Bioética, Brasília, DF, v. 4, supl. 2, p. 1525, 1996.

DUARTE, G. A. et al. Participação masculina no uso de métodos contraceptivos. Cadernos de Saúde Pública, Rio de Janeiro, v. 19, n. 1, p. 207-216, 2003.
ENGLE, P.L.; LEONARD, A. Los padres como compañeros en la crianza de los hijos In: BRUCE, J.; LOYD, C.; LEONARD, A. La familia en la mira: nuevas perspectivas sobre madres, padres e hijos. New York: Population Council; 1998. p. 49-69.

GLASIER, A. Acceptability of contraception for men: a review. Contraception, Nova York, v. 82, n. 05, p. 453-456, Nov., 2010.

HOFMEYER, D.G.; GREEFF A.P. The influence of a vasectomy on the marital relationship and sexual satisfaction on the married man. Journal of Sex \& Marital Therapy, London, v. 28, n. 4, p. 339-351. July/Sept., 2002.

HOWARD, G. Who asks for vasectomy reversal and why? British Medical Journal, (Clinical research ed.), London, v. 285, n. 6340, p. 490-492, Aug. 1982.

JAMIESON, D. et al. A comparison of women's regret after vasectomy versus tubal sterilization. Obstetrics and Gynecology, New York, v. 99, n. 6, p. 1073-1079, June 2002.

LABRECQUE, M. et al. Evaluation of the effect of a patient decision aid about vasectomy on the decision-making process : a randomized trial. Contraception, New York, v. 82, n. 05, p. 556-562, Nov. 2010.

MANHOSO, F. R.; HOGA, L. A. K. Men's experiences of vasectomy in the Brazilian public health service. International Nursing Review, Oxford, v. 52, n. 2, p. 101-108, June 2005.

MARCHI, N. M. et al. Opção pela vasectomia e relações de gênero. Cadernos de Saúde Pública, Rio de Janeiro, v. 19, n. 4, p. 1017-1027, 2003.

MARCHI, N.M. et al. Vasectomy within the public health services in Campinas, São Paulo, Brazil. International Nursing Review, Oxford, v. 57,n. 2, p. 254-259, June, 2010.

MELVILLE, C.; BIGRIGG, A. Male and female sterilization. Obstetrics, Gynaecology and Reproductive Medicine, Oxford, v. 18, n. 12, p. 330334, 2008. 
MILLER, W. B.; SHAIN, R. N; PASTA, D. J.

The Pre-and Poststerilization Predictors of Poststerilization Regret in Husbands and Wives. The Journal of nervous and mental disease, Hagerstown, MD, v. 179, n. 10, p. 602-6o8, Oct. 1991.

MINAYO, M. C de S. O desafio do conhecimento, pesquisa qualitativa em saúde. 4. ed São Paulo: Hucitec; Rio de Janeiro: ABRASCO; 1998.

MINELLA, L. S. Aspectos positivos e negativos da esterilização tubária do ponto de vista de mulheres esterilizadas. Cadernos de Saúde Pública, Rio de Janeiro, v. 14, Supl. 1, p. 69-79, 1998.

OSIS, M. J. D. et. al. Conseqüências do uso de métodos anticoncepcionais na vida das mulheres: o caso da laqueadura tubária. Cadernos de Saúde Pública, Rio de Janeiro, v. 15, n. 3, p. 521-532, 1999.

OSIS, M. J. D. Laqueadura e representações acerca da sexualidade e do papel reprodutivo. 2001. 196 f. Tese (Doutorado em Saúde Materno-Infantil) Faculdade de Saúde Pública, Universidade de São Paulo, São Paulo, 2001.

OSIS, M. J. D. et al. Atenção ao planejamento familiar no Brasil hoje: reflexões sobre os resultados de uma pesquisa. Cadernos de Saúde Pública, Rio de Janeiro, v. 22, n. 11, p. 2481-249o, 2006.

PHILLIBER, S. G.; PHILLIBER, W.W. Social and psychological perspectives on voluntary sterilization: A review. Studies in family planning, New York, v. 16, n. 1, p. 1-29, Jan./Feb. 1985.

PILE, J. M.; BARONE, M. A. Demographics of vasectomy - USA and international. The Urologic clinic of North America, Philadelphia, v. 36, n. 3, p. 295-305, Aug. 2009.
POTTS, J. M. et al. Patient characteristics associated with vasectomy reversal. The Journal of urology, Baltimore, v. 161, n. 6, p. 1835-1839, June 1999.

RODRIGUES, A. et al. The consequences of the vasectomy in the quality of life in a Brazilian family planning program. European Urology Supplemments, Oxford, v. 2, n. 1, p. 121, Feb. 2003.

RUGBY, J. A. et al. Vasectomy: who regrets it and why? Ugeskrift for laeger, Copenhagen, v. 156, n. 16, p. 2377-238o, Apr. 1994.

SEIDEL, J. The ethnograph [software]. Version 5.0 Salt Lake City (UT): Qualis Research Associates, 1998.

SMITH, A. Are sexual problems more common in men who have had a vasectomy? A populationbased study of Australian men. The Journal of sexual medicine, Malden, MA, v. 7, n. 2, p. 736-742, Oct. 2009.

SERRUYA, S. Mulheres esterilizadas: submissão e desejo. Belém: UFPA-NAEA/UEPA, 1996.

SONFIELD, A. Contraception: An integral component of preventive care for women. Guttmacher Policy Review (online), v. 13, n. 2, p. 2-7, 2010. Disponível em: <http://www.guttmacher. org/pubs/gpr/13/2/gpr130202.pdf >. Acesso em: 14 mar. 2011.

THONNEAU, P.; D'ISLE, B. Review does vasectomy have long-term effects on somatic and psychological health status? International Journal of andrology, Oxford, v. 13, n. 6, p. 419-432, Dec. 1990. 